\title{
Prospective Thinking; \\ Scenario planning meets neuroscience
}

Peter McKiernan

\begin{abstract}
The Intuitive Logics (IL) scenario planning process is grounded in the work of Hermann Kahn and Pierre Wack in the 1960s and 1970s. Its broad adoption and sustained use over 50 years has taken it beyond the typical management fashion or fad. It has helped shape the strategies of many types of institutions and organisations. The process encourages individuals to recall past events and to imagine future happenings. But, little is known about neither how they do this nor the contextual conditions that shape how they do it and how they might do it better. Recent developments in cognitive psychology and neuroscience have had success in several management domains e.g., marketing, information systems, leadership, economics and finance. However, little attention has been paid to their application in strategic management and, in particular, in scenario planning. The paper provides a critical coverage of the pertinent cognitive sciences literature and explores opportunities for co-joint research between scenario planners and cognitive psychologists that might help to further foster and support the IL process.
\end{abstract}

\subsection{Introduction ${ }^{1}$}

Scenario planning (SP) has progressed beyond fashion. Systemic practical coupling with strategic planning, broad adoption across the organisational spectrum and sustained academic research has moved it beyond the tight 'bell shaped' curve of the management fad (Abrahamson, 1991; Gill and Whittle, 1993). Now, it is embedded firmly in strategic management discourse and praxis (Cummings and Daellenbach, 2009). But, its continued and increased utility will depend on continuous innovation (see, for example, Bradfield et al, 2016). In exploring a cognate field to inspire such innovation, this paper acknowledges the scholarly call for more inter- and multidisciplinary work in management studies and SP studies in particular.

In this reflection, the unit of analysis is the 'intuitive logics' (IL) scenario process. Stemming from the work of Hermann Kahn at the RAND Corporation and the Hudson Institute in the 1950s and 1960s (Kahn, 1960; 1962), the IL process was imported into Royal Dutch Shell ${ }^{2}$ in the late 1960s. This mainly qualitative approach was an intellectual challenge to the highly quantitative forecasting approach

\footnotetext{
${ }^{1}$ I am grateful for the supportive feedback from 4 anonymous reviewers and from the special issue editor in chief, George Wright. In addition, Anil Patel provided critical commentary on the scenario planning sections and Mike Anderson provided advice and critique on the cognitive psychology and neuroscience sections. I am indebted to them both.

2 Ted Newland imported the scenario ideology into Shell, where it was refined with Henk Alkema,

Pierre Wack and Napier Collins, amongst others influential members of Group Planning (Wack, 1985a; 1985b; Bradfield et alia, 2005; Wilkinson \& Kupers, 2013; Patel, 2016).
} 
embodied in the Unified Panning Machinery ${ }^{3}$ that embraced the organisation throughout the 1960s and into the early 1970s (Kleiner, 1996). After significant internal development and varying success levels, senior planning group staff later promulgated the benefits of scenario planning to the broader worlds of consultancy ${ }^{4}$ and academia e.g., Schwartz, 1991 (Global Business Network) and Van der Heijden, 1996 (University of Strathclyde).

Normally, the IL process progresses from the stage of Diagnosis to that of Scenarios to Strategy Process, by way of the stages of Data Collection, Analysis, Synthesis, Exploration of Key Issues, Scenario Building, Scenario Writing, Scenario Testing, and Refining (see Figure 1 and the accompanying Table 1-for a fuller description of the stages). The stages are linked and there is some circularity in the process through feedback loops. These feedback loops have the hallmarks of a creative process (Poincare, 1913; Weisberg, 1993) by inclusion of ideas generation, artful facilitation, scientific modeling, the weaving of novelty with surprise and practical utility. This combination of art in expression and illumination combined with the science ${ }^{5}$ of cause and effect modeling has proven powerful and effective in exploring the varied future contexts for many kinds of institutions and organisations. But, like most creative processes, dysfunctions are embodied within its stages, e.g., failure (Hodgkinson \& Wright, 2002), discontent (Livingstone et al, 1997; Miron et al, 2004), job dissatisfaction (Zhou \& George, 2001), and dislikes of innovative behaviour and destructive conflict (Janssen, 2003; 2004).

Despite these limitations, the Il process still shapes most qualitative futures projects, and its use has spread to include other organisational issues e.g., the influencing of social and political agendas, the fostering of learning and development and the assessment of organisational risk. But, finding further process improvements through incremental innovation within existing knowledge boundaries and frames is difficult to achieve. An exploration of previously unexplored domains may provide more fruitful results. Essentially, the IL process offers individuals an opportunity to imagine longer futures than they would do normally. Yet, little is known about the cognitive processes of how they do this and what the contextual conditions are that

\footnotetext{
3 “In 1965 Royal Dutch Shell put into service what it called the Unified Planning Machinery (UPM), a computer-driven system meant to bring more discipline to the company's cash flow planning. This kind of rational, model-based financial forecasting was very much in vogue in the 1960s. But before long, Shell's top executives realized that many of the commitments they had to make extended well beyond UPM's six-year time horizon - and that even within that horizon, UPM tended to get a lot wrong." Wilkinson \& Kupers, op cit

${ }^{4}$ Though, the US Department of Defense, Stanford Research Institute (now SRI) and Battelle had incorporated scenarios into their strategy work before; in these early adopter days, the various actors knew each other well and influenced the various developments co-jointly e.g., Schwartz was at SRI, then Shell then GBN.

5 This combination of art and science is unusual amid techniques in the strategy arsenal. The exploration of the effects of each individually, and together in combination, on scenario planning is an unexplored avenue- ripe for research. The introduction of the cognitive sciences in this paper is one approach to articulate the linkage from science to arts, especially in terms of organizing effective scenario workshops and building more creative scenarios. However, there is little evidence in the scenario planning literature, nor anecdotally amongst academic and practical scenario players, of any rift between researchers steeped in one background or another; as CP Snow alluded to in his 1959 REDE lecture, when he lamented on the gap between these "Two Cultures".
} 
that shape how different individuals do it. Promisingly, recent research in neuroscience has examined how people remember the past and imagine the future. It has begun to uncover the neural networks deployed by different people under different conditions (Schacter et alia, 2015). This paper marries elements of this promising new arena together with the IL process in order to offer opportunities for innovation in the exploration of prospective thinking ${ }^{6}$. These include the notion of 'futures rehearsals', the use of strong, data collection filters and the design of groups in scenario workshops.

Operational definitions used in this reflection are included in Table 2, below. Three further sections follow this introduction. The next section examines critically the cognitive sciences literature, looking both at their natural domains and where they have informed the business and management agenda. Section three provides six opportunities for co-joint research between scenario planners and psychologists, in an attempt to improve the IL process through innovative activity. This section includes a short vignette that illustrates both stages of the IL process and how further research might influence the process. A summary and conclusion follows that highlights the likely main impact of the cognitive sciences domain on the IL process and offers up a research challenge to social scientists.

Figure 1: The Intuitive Logics Scenario Planning Process

TABLE 1: Stages of the Intuitive Logics Scenario Planning Process

(Note: There is some circularity in the stages and not all stages are included in any one process

TABLE 2: Definitions employed

\footnotetext{
${ }^{6}$ Prospective thinking is similar in nature to the parallel concepts of pre factual thinking (Sanna, 1996) and forethought (Bandura, 2001) in that is involves people creating simulations of future events and working through their consequences for themselves and for others. On the other hand, rehearsals can be both past and future orientated as training in the experience of a recent experience or scene setting of people, places and objects for future imaginings.
} 


\subsection{Cognitive Sciences ${ }^{7}$}

\subsection{Perceptions and Cognition}

Managerial perceptions and their effect on environmental decoding and associated strategic action have a progressive pedigree in strategic management (Kaplan, 2011). Originating in social psychology (see, for instance, Fiske \& Taylor, 1984) and acting as a counterbalance to the dominance of the assumptions and prescriptions of industrial economics, scholars engaged increasingly with interpretative linkages from the cognitive sciences to strategic management (e.g., Huff, 1982; Spender, 1989; Walsh \& Fahey, 1986). Specifically, the view that environments were determined exogenously was challenged and the process by which the perceptions and frames of managers in shaping them in an endogenous way, came to the fore ${ }^{8}$. External complexities required decoding through managerially constructed 'frames' (Daft \& Weick, 1984) that act as simplifying filters, and so help overcome limits to comprehension (March \& Simon, 1958).

Early investigations ${ }^{9}$ into how managers perceive elements of their environment, especially intra-industry rivalry (McGee \& Thomas, 1987), industry recipes (Spender, 1989) and competition (Porac et alia, 1989), laid the foundations for the spread of managerial cognition into many management fields. Kaplan (op cit) interprets this proliferation as a stage-based evolutionary process that follows the validation of measures of cognition (Milliken, 1990) with the testing of a manager's cognitive accuracy (Sutcliffe, 1994); the linking of cognition to strategic outcomes (Barr, 1998); and the analysis of the interaction of cognition in dynamic models of organisational action (Rouleau, 2005; Kaplan, 2008a). Later work has refined 'situated cognition'10 into momentary or temporal perspectives (Elsback et alia, 2005) and married the interaction of cognition with the internal, competitive political process of strategy formation (Kaplan, 2008b).

Besides leveraging cognition to the strategy agenda, this body of work has evolved both deeply (e.g., in construct measurement and validity) and broadly (e.g., across many areas of organisational management). Like most developing fields, this process was not without its pauses for reflection and re-calibration (see, for instance, Walsh, 1995). Such self criticism is accompanied by other charges, e.g.: a) its roots in the Academy of Management led to a US-dominated view in its early trajectories (and, some might argue, its later ones, too) making knowledge exchange beyond large 'for profit' contexts difficult; $b$ ) the biases inherent in its case-based empirical work made such transfer equally difficult; and c) the reliance on corporate, annual report letters as proxies for longitudinal data is hampered by their narrative being governed by direct and indirect PR messages to stakeholders. However, the legacy remains strong, especially with regard to the perceptual filters employed by managers to view contemporary contexts and perhaps, imagine their futures.

\footnotetext{
7 This section is informed by discussions with Mike Anderson, Professor of Psychology at Murdoch University.

${ }^{8}$ Though Hermann Kahn and Pierre Wack had worked on the assumption of endogeneity of environments many years before in their pioneering scenario work (see Wack, op cit)

${ }^{9}$ For reviews of the field in the early days, see Walsh op cit, and Hodgkinson (1997).

${ }^{10}$ As defined by Elsbach et alia, op cit, situated cognition is a momentary perception in managerial environmental sense-making.
} 


\subsection{Scenario Planning and Cognition}

Scenarios can be seen as story-based cognitive 'filters' in the process of sense making, sense giving and sense receiving, ${ }^{11}$ amidst managerial environmental interpretation (see, for instance, Gioia \& Chittipeddi, 1991; Hodgkinson \& Healey, 2008). Specific research has concentrated, inter alia, on its story telling features (Coleville et alia, 1999; Boje, 2008; Bowman et alia, 2013;) and the ability of the stories to unlock calcified managerial mindsets (Boje, 1991; Schoemaker, 1995: Gardner, 2000; Jefferson, 2012) and allow them to become more creative. But, the actual internal, cognitive networks of individuals and groups remained illusive until breakthroughs in neuroscience technology e.g., fMRI, and the introduction of neuroscience pathways into recalling the past and imagining the future, for example, through an SP process.

In strategic management, such interdisciplinary research (Laureiro-Martinez et alia, 2015a) on the nature of managerial ambidexterity (the exploration of new knowledge and the levering of existing knowledge) has shown that a) exploitation is linked to those regions of the brain that expect reward while exploration is linked to those that deal with attentional control and that $b$ ) each of exploration and exploitation employ different cognitive processes. Moreover, it seems that entrepreneurs have higher decision-making efficiency than managers and more brain activity in those areas associated with explorative choice (Laureiro-Martinez et alia, 2014). For adaptation to ever changing contexts through the superior tracking of constantly evolving options, this result augurs well for the generation of multiple and broader future perspectives. While such exploration is a key to unlocking creative future thinking in scenario planning, a tracing of the historical roots of this research pathway helps to tease out other cognitive influences on future thinking.

\subsection{Memories of the Future}

Since its inception, research in the cognitive sciences has had a strong historical perspective. It had a...

"driven by the past framework ${ }^{12}$...in which habits and drives were claimed to be universally applicable models of learning, memory, decision-making, motivation and cognition” (Seligman et alia, 2013, p136).

This included behaviourism and Freudianism. Prospection and the prospective brain that imagined the future and a range of possible future scenarios were largely ignored.

So, memory research for much of the $20^{\text {th }}$ century focused on the cognitive processes that allowed people to store and recall information from the past. This memory conceptualization of the past influenced much research in the cognitive sciences for decades after Bartlett's (1932) original propositions in his famous 'theory of remembering'. Here, social conditions were shown to be influential in recalling

\footnotetext{
11 Sense receiving is a new term that describes the receptiveness of an individual or group of individuals to the sense-giving messages of others. It is a mental attitude that, according to the degree it is exhibited, influences the cognitive processes of sense making and decision-making (MacKay and McKiernan, forthcoming).

${ }^{12}$ Author's italics
} 
stories. According to Bartlett, people assimilate detail from the past in the context of their own present - for example, 'canoes' in a North American Indian story became 'boats' when recalled by English Edwardians in their own context during Bartlett's experiments ${ }^{13}$.

Besides these changes from the nuancing of language, the brain's recall and is distorted with error or commissioned 'sins' (Schacter, 1999). This fallibility is important, as it asserts that memory does not produce a digitally perfect reproduction of the past (Anderson and Schooler, 1991). Because the brain searches for as much of the stored data from its various compartments as it can, and then pieces these together in the construction of a 'memory jigsaw', it produces the best possible replica of the past event(s) that it can manage. It stores memory in this scattered way, rather than a replicative way, to avoid overload. Error happens because the brain may draw upon the wrong schemata (see Bartlett, op cit) or 'mingle the memory materials', so the jigsaw pieces for a single event may be made up from retrieved data from similar events. Trapped with a focus on the past, the missing feature in much of this work was how memory influenced people's imagination of the future and the importance of linking the past, through the present, to the future (Suddendorf \& Corballis, 1997; Schacter and Addis, 2007; Szpunar et al, 2014). Is mental time travel possible?

Not until the classic work of Kahneman and Tversky (1973) were such links from the past e.g., recall of events, to the simulation of future events connected. Their results suggested that the probabilities of an event happening in the future were higher if subjects could recall something similar in the past. More, if an event had not happened before, subjects made up scenarios of the future. The easier the scenario was to build, the higher the probability given to its' happening (the simulation heuristic). ${ }^{14}$ Later, Ingvar $(1979 ; 1985)$ continued to make the past-future links by examining 'Memories of the Future' though brain simulations. His early work observed blood flow concentrations in the brain's prefrontal cortex while subjects rested, indicating that this area is crucial for planning and foresight activity. He concluded that:

“...the brain...is automatically busy with extrapolation of future events and, it appears, constructing alternative hypothetical behavior patterns in order to be ready for what may happen.” (Ingvar, 1979, $\mathrm{p} 21)$

Sadly, as Schacter et al (2008) have asserted, these ideas on 'memory based future events' gained little ground in research at the time.

However, the turn in modern cognitive science research has built on Ingvar's ideas and, with the onset of modern technology (e.g., fMRI), to probe more deeply into the neural networks of the brain that link the past to the future. Such technology, coupled with more traditional research designs using university students, has opened up a new understanding of the past-future cognitive linkages.

\footnotetext{
${ }^{13}$ Bartlett referred to this phenomenon as 'conventionalisation'; it helped shape his great work on schemata that influenced many subsequent works in the cognitive sciences.

${ }^{14}$ Unfortunately for Scenario Planning, research on this heuristic has been parsimonious, beyond the realm of psychopathy (Raune et al, 2005; Schacter et al, 2008).
} 


\subsection{Episodic Futures}

Recent memory research has been inspired by developments in neuroscience. Much has focused upon episodic memory -the recollections of events in a person's past (Tulving, 1985), and how these shape future imaginings. Episodic memory ${ }^{15}$ allows people to perform mental time travel and experience a past happening again and to pre-experience events that might happen in the future (Suddendorf \& Corballis, 1997). Botzung et alia, (2008) conjecture that a common neural network exists that allowed individuals to recall past events and predict future ones from the ages of three to five years old. More, they asserted that the factors influencing past recall and future prospecting (e.g., imagery, distance in time) were the likely to be the same.

Employing neuroimaging and neuropsychology, Harvard psychology professor, Daniel Schacter and his colleagues, have brought this research to the forefront of cognitive neuroscience. His underlying tenet is that a critical function of the brain is as a store of knowledge to facilitate the imaginings of future events - the prospective brain. Consistently over the last decade, their work has emphasized that memory is crucial in informing future imaginings based upon a close similarity in the 'cognitive and neural processes' that are engaged in recalling the past and thinking about the future (Schacter \& Madore, 2015).

These similarities are in contextual features (Szpunar \& McDermott, 2008); self-focus (Rathbone et al, 2011) and, crucially, in a common neural configuration in the brain the core network (Schacter et al, 2007) ${ }^{16}$. Moreover, neuroimaging experiments (involving fMRI) have shown that there are sub systems of this core system that light up more on remembering the past and other sub-systems, like the hippocampus and frontopolar cortex, that light up more on imagining the future e.g., (Addis et al, 2009). The increased hippocampus activity associated with future imaginings may be due to two things (Schacter et al., 2013). First, the original imagination of the future requires a considerable investment from the brain, more so than recalling the past. Second, the brain has encoded much of the past already, but future imaginings have to be coded $a b$ initio and so, the brain has to work harder. Delving deeper into the future oriented sub system of the core network, certain parts have been identified with future thinking e.g., simulating people - dorso-medial prefrontal cortex; objects - inferior frontal and premotor cortices and locations - retrosplenial, parahippocampal and posterior parietal cortices (Szpunar et al., 2013; Hassabis et al., 2013).

In addition, researchers using fMRI technology have implicated the same networks as responsible for counter factual thinking, where the brain is tested once again for originality of imagining and initial encoding (Van Hoeck et al., 2012). However, the counter factual element may involve the brain using prior encoded material of similar events, while the future imaginings can represent 'pure' creative constructs:

\footnotetext{
${ }^{15}$ Episodic memory is different from semantic memory - general knowledge, and procedural memory skills and routines.

${ }^{16}$ The core network consists of the medial temporal cortex, the medial prefrontal cortex, posterior cingulate, retrosplenial cortex, and lateral temporal and prefrontal regions (Schacter et al, 2013).
} 
"Though episodic future thinking and episodic counter factual thinking require similar constructive processes, these operate on material that is differentially constrained by reality. The future is inherently uncertain, and thus there are many degrees of freedom in simulating prospective episodes, and any mental mutation of the past may clash with our knowledge of the events wider context".

(Schacter et al., 2013, p17)

Basically, a lack of a template for pure creative events makes future imagining challenging for the brain to do. As such prospective imaginings might occur, while counterfactual ones from the past simply cannot occur, the controllability of hypothetical futures might be more constrained (Ferrante et alia, 2013). Studies have shown that when people imagine a future scenario repeatedly, their belief in its occurrence rises significantly (Caroll, 1978). This result also applies to the subset of people, objects and locations (Szpunar \& Schacter, 2013). How repeated simulations affect the resultant behaviour is a promising area for future research. Because such simulations allow individuals or even groups to imagine or 'pre-feel' their place in a future scenario, repeated future imaginings might be linked strongly to long-term strategy or decision- making (Gilbert \& Wilson, 2007; Schacter et al., 2013). This emotional component, or lived future experience, could play a key role in any behavioral responses in the present, despite the context of the future imagined event being different from that of today.

\subsection{Non-Episodic Futures}

In synthesis, episodic memory is important in constructing imaginings of future scenarios but it may not do this alone. Semantic memory - which supports general knowledge, may influence individuals' perceptions of past happenings and future prospecting (Irish et al, 2012; Klein, 2013). When recalling events in the past or imagined futures, older adults seem to recall less episodic internal detail - who, when and where type facts, and more general external information - related facts, reflections, inferences about saliency, than younger adults (Addis et al., 2008). Researchers claim that these age differences are due to changes in episodic memory mechanisms (Rendell et al., 2012) but, other age-based experimentation (Schacter \& Madore, op cit) has suggested that, even when episodic memory is not taxed, older adults tend to be less descriptive on detail and more inferential or comparative in their commentary.

To help distinguish between the episodic and non-episodic influences on past-future thinking, Madore et al., (2014) experimented with episodic specificity induction i.e., training in the experience of a recent experience. Using the Cognitive Interview (Fisher \& Geiselman, 1992) ${ }^{17}$, they rehearsed a past event with participants. Interestingly, there was an increase in the episodic, internal (e.g., on-topic and episodic) detail of recall of both older and younger adults ${ }^{18}$, but no effect on the number of semantic, external detail for recall or imagination. Further work, using different experiments, confirmed this general finding (Madore \& Schacter, 2015; 2016). This suggested that:

\footnotetext{
${ }^{17}$ A technique used to increase event recall in eyewitnesses that is designed to maximize the accuracy of memory retrieval and minimize misinformation and false memories. Memory fades with time and so it is important to encode information as soon as feasible and ensure that the conditions at encoding are as close as possible to the conditions at the time of retrieval.
} 
"...age related changes in remembering the past and imagining the future reflect primarily the operation of non episodic mechanisms, such as changes in narrative style or communicative goals that occur with ageing and could affect performance similarly on memory, imagination, and picture description tasks." (Schacter \& Madore, 2015, p6)

These rehearsals have been likened to scene construction (Hassabis \& Maguire, op cit.) of people, places and objects and how these might form mental images or stage settings of the past or future imaginings. Rehearsed scenes that can be recalled aid adaptability in the future, especially in crisis situations. Scientists have pondered over what variables influence the brain to encode a scene and store it as a 'memory of the future' (see Ingvar, op cit). The working hypothesis is that when thinking about future scenes that have similar components to experienced scenes, people rely on episodic memory. When thinking about unfamiliar future scenes, they rely more on semantic memory, especially on information from external sources (Klein et alia, 2012; Anderson, 2012). McLelland et alia, (2014) showed the significance of people familiarity (not objects or locations), the amount of detail in the scene and its personal plausibility in the brain's capacity to encode a scene. They claimed that the way to a memorable future is through 'scaffolding future simulations with pre-existing episodic memories' (McLelland et alia, 2014, p1).

However, such studies rely on participant's scene familiarity and so on future scene construction that is similar to past scenes. Importantly, scene construction involves imagining scenes that do not rely on episodic memory alone, but are more generic in their settings- like scenarios of the future. Human and organisational adaptation requires the mental capability to imagine future scenes that are unfamiliar, but could happen. It may be the case that general settings draw upon some part of individual episodic memory, but the extent is not yet known.

By incorporating 'disparateness' of scene details into their research, van Mulokom et alia (2016) help elucidate this puzzle. They investigated the recall of participants within and across three social spheres (e.g., Hiking Club, Friends, Family). Scenes created within spheres were rated as more plausible and remembered most often than cross sphere scenes (the unfamiliar ones). Interestingly, cross sphere scenes were seen as happening in deeper futures than familiar ones and required much more constructive effort while pre-existing memories dominated scene recall.

\subsection{Neuroscience Research in Management}

Such scene imaginings in deep and near futures have many parallels in scenario planning workshops, as participants grapple with thinking about states both at the project time horizon (e.g., 20 year hence) and the beginning of the journey to that horizon. Unfortunately, it is other social science scholars ${ }^{19}$ who have grasped the many opportunities presented by modern neuroscience technologies (Powell, 2011). In particular, the use of physiological methods ${ }^{20}$ has a long history in marketing research. Despite being a relative newcomer, the most popular neurophysiological method $^{21}$ is functional magnetic resonance imaging (fMRI) (Suomala et alia, 2012).

\footnotetext{
${ }^{19}$ For example, those in law, political science, leadership, human resource management, anthropology, sociology and strategic management
} 
The sustained use of fMRI scanning has been in neuroeconomics (Glimscher, 2011), particularly in experimental games (Rustichini, 2005); in neuroinformation systems studies (Dimoka et alia, 2011), particularly in uncovering the brain areas for trust and distrust (Dimoka, 2010); and most commonly in marketing (Eser et alia, 2011), where a raft of popular books has emerged recently. Here, marketeers focus on the brain's pre-frontal cortex; when it lights up, consumers are more likely to be pleased and so make a purchase. Hence, fMRI has been used extensively, e.g., in explaining consumer preferences for Coke versus Pepsi (McClure et alia, 2004c); in investigations of consumer choice regarding controversial food technologies (Lusk et alia, 2015); and, unsurprisingly, in the forecasting of chocolate sales (Kuhn et alia, 2016). Indeed, Dimoka et alia (2011) claim that a unified theory of human behaviour is being formed under the 'umbrella of cognitive neuroscience in the social sciences'.

In a short time, this particular body of cognitive science has been influential and is cited heavily. The combination of traditional cognitive psychology methods coupled with recent technological approaches has yielded replicative results but the approach has its critics. First, here has been concern over the ethical use of fMRI (see Eser et alia, op cit, and Laureiro et alia, 2015b), especially in marketing experiments for products and services where neurologists and practitioners see it as more acceptable than academics do. Second, research utilizing this technology is costly and depends largely on the accessibility of the appropriate scanners. More, diverting precious resources to it would incur large opportunity costs of doing penetrating research elsewhere (Dovidio, et alia, 2008).

Third, critique has been leveled at the interpretation of neuroimaging results (Logothetis, 2008) due to the naivety of simple mapping in a complex organ and comparability, given the different resolutions of different brain imaging tools used in earlier work. Fourth, much of this research ignores plasticity ${ }^{22}$, as it is conducted on healthy subjects. Fifth, generalized results have to account for inter-subject variability through the modeling of spatial smoothing (Dimoka et alia, op cit; Price \& Friston, 2005). Sixth, its effectiveness across the social sciences may not be universal. For example, in strategic management, Powell (op cit) has questioned its utility because strategy deals with aggregations at the firm, strategic group or industry level and not at the 'reductionist' level of individuals and teams, upon which neuroscience focuses. Seventh, fallacious results may occur by allocating significance to an isolated brain function when the brain is part of a larger 'whole' and it is the whole that thinks, feels, believes and sees (Bennett \& Hacker, 2003). Clearly, with advances in technology and an exponential growth in research output, the neuroscience domain will be around for a while longer and its impact judged on its ability to continue to replicate results and how these will outcomes will benefit society broadly and further research specifically.

In particular, its engagement with scenario planning seems natural, as the general theme of scenario planning deals with recalling the past and thinking about the future, which is precisely the theme of this specialist field of neuroscience. Surprisingly, Powell's (op cit) review of neuroscience in strategy pays no attention to this foresight dimension. Though little research has been done specifically in this area, it is evident

\footnotetext{
${ }^{22}$ Non-healthy subjects may have brain injuries that cause plasticity. This can reorganize the neural pathways and impact on functionality.
} 
that other management researchers have experimented broadly with cognitive neuroscience and helped to establish some legitimacy for its technology in their research method and findings. So, what opportunities ${ }^{23}$ does this field present for SP?

\subsection{Opportunities for Interdisciplinary Research}

The cognitive sciences present several opportunities for scenario planners using an IL process. Opportunities are general to the process and specific to individual stages within it. ${ }^{24}$

\subsection{General Opportunity}

Neuroscience experimentation, especially that based upon Schacter and Addis's (2007) constructive episodic simulation hypothesis (CESH) - whereby episodic memory supports the construction of imagined futures, may provide direct benefits for scenario planning. SP links the past, through the present to the future through the general analysis of socio-technological-economic-environmental-political-security factors that leads to the identifications of trends and uncertainties and the construction of scenarios and how these articulate to strategic visioning, key success factors and strategy formulation and implementation (see Schoemaker, op cit). More, unlike the high aggregation level of the units of analysis used elsewhere in strategic management, SP deals with individuals and smaller groups e.g., management teams, and so compares more directly with the experimentation in neuroscience.

\subsection{IL Linking Process Stages to Specific Opportunities}

\section{Opportunity 1}

Most SP processes have a common need to gather information from people, either in individual or group formats, through individual and group interviews or Delphi processes. The extent to which each participant has a personal interest in either a discrete, or a range of, scenario outcome(s) varies (Courtney et alia, 1997). Hence, a word of caution is appropriate. Episodic personal imaginings are likely to be different from general future prospecting that contains no self-referencing. Much research on general prospecting e.g., in the cognitive sciences or behavioral economics, is based upon hypothetical scenarios that don't register personal experience (Roese \& Olsen, 1995). As Schacter et al., (2015) point out, recent counterfactual experimental results (e.g., Pighin et al., 2011) show a difference between outcomes for thinking about personal, as opposed to non personal, events. The extent of personal experience in the scenario process, such as a dominant CEO or the owner-managers in a small or medium sized firm might have, is likely to be an important influence on both the scenario process and its strategy outcomes. If an individual or group of individuals has a strong personal interest in the recollections or future imaginings then a bias may be built into the process at the outset (project scoping). Cognitive scientists do not

\footnotetext{
${ }^{23}$ In recent years, neuroscience has presented opportunities in Information Systems (Dimoka et alia, op cit,) in studies of leadership (Waldman et alia, 2011) and in strategic management (Powell, op cit)

${ }^{24}$ The opportunities suggested are not exhaustive.
} 
know enough yet to identify precise differences and what they mean. Hence, scenario planners should watch the discussion of episodic versus general prospecting closely over the coming years. Nonetheless, important research questions are raised for the scenario process e.g., do scenario processes which involve participants who are closely related to the scenario set's future activities and outcomes differ substantially from those created by participants whose interests are less correlated with them? How does such participant relatedness matter for the types of strategy repercussions suggested by the scenarios?

\section{Opportunity 2}

CESH results have established that age is a significant variable. Older adults tend to recall less episodic internal detail and use more semantic external detail than younger adults, perhaps due to the effects of the ageing process (Schacter et alia, 2015). Age is significant in the scenario process as it could form one of the key design criteria for producing a balanced scenario set. The age of the participants in the data collection stage, and in the scenario-building workshop could influence the nature and content of the eventual scenarios produced. An overburdening of either sample by older people is likely to deliver less detail in recollections of the past, but provide more comparative and inferential commentary. Equally, an excess of younger adults might mean a study rich in detail but with little external embellishment ${ }^{25}$. Of course, there will be exceptions to these age related findings but they do suggest that the scenario building objective of creating expansive, multiple perspectives coloured with detail might require a mixed age group. Again, this argument generates research questions e.g., when working in groups; do older people create more generalizable scenarios than those created by younger people? When working in groups, do younger people generate more detailed scenarios than older people?

\section{Opportunity 3}

Linked to age, episodic memory enhancing strategies have been shown to increase the detail of recall of past events and so enhance future imaginings. In particular, the cognitive interview (Fisher \& Geiselman, op cit) surpasses ordinary interviews by as much as $12 \%$ points in the accuracy of recall in eyewitness accounts (Geiselman et alia, 1985). Madore, et alia ( op cit) found that the technique increased the recall of episodic detail in both younger and older adults but it did not affect semantic memory or imagination. Consequently, they found that the age related differences in recall were due to non- episodic factors like narrative style, inhibitory control or communication goals (the way older people speak e.g., off-topic) associated with ageing.

From this research, at least three opportunities present themselves for the IL process. First, the cognitive interview (or an adaptation) might be used to capture more detail in recall and develop more detail in imagination. In recall, the technique purposely alters the narrative order by demanding recall from the earliest detail to the latest (to

\footnotetext{
${ }^{25}$ More, the CESH results might explain un-researched observations in SP, e.g., why scenarios generated by youthful communities seem to be richer and more expressive than traditional organizationally based ones.
} 
overcome people's tendency to recall recent events first). More, it causes the individual to juxtapose their standpoint and see the event through the eyes of another actor in the scene. Altering the recall order would be helpful when establishing accuracy in the historical credentials of an organisation (like key players, key teams, key competitors etc.) in the data-gathering phase. Changing the standpoint would be useful in enhancing a scenario in the scenario building stage and then in the testing stage, in checking for plausibility, internal consistency, comprehensiveness and surprise. Second, scenario planners will need to pay further cognizance to nonepisodic mechanisms in enhancing recall and future imaginings. In particular, if older people dominate a steering group or interview sample, then investigating their narrative styles and communication goals may be essential in maximizing their imagining capacity.

Finally, while the cognitive interview helps gain accuracy of recall by rehearsing the past, it may be that an equivalent technique might be developed for rehearsing future imaginings ${ }^{26}$. For many participants, immersion in a scenario project and especially a scenario workshop is a novel experience. Many participants question the legitimacy of working in an incomprehensible deep futures space when their daily routines require only near future thinking. Their ability to think into deeper futures can be limited further by conservative management styles that, culturally, can lock many into the 'here and now'. To try and overcome such resistance, an attempt at a 'future rehearsal' was used in a recent scenario project at the scenario building stage (see Vignette 1). Again, more research and development is required if such techniques to aid creative imagination and to enrich detail are to become active parts of an IL process.

These arguments suggest that scenario research might consider using the cognitive interview to explore research questions such as: Does the use of the cognitive interview lead to richer recall of history? How do different narrative styles and communication goals influence the content of scenarios? Do structured rehearsals lead to richer scenarios in deep futures than non- rehearsed ones?

\section{Opportunity 4}

Strategically, building 'Memories of the Future' is critical. Memorable scenario names and vivid dramatisations ${ }^{27}$ that trigger content recall have long been an essential part of the IL process. The ability to recall a scenario, or a set of scenarios, is essential if the strategic response is to be timely and effective, while the life of the scenario set plays out. Signposts embedded in the scenario logics help in identifying the milestones and directional movement but its effectiveness comes with pinning the scenario detail in the minds of agents with the power to act.

\footnotetext{
${ }^{26}$ Cognitive scientists have warned that of the dangers of over-rehearsing and how repeated simulations can lead to significant increases in the perceived plausibility that events would occur (Szpunar \& Schacter, 2013); though, little is known their influence on later behaviour.

${ }^{27}$ Examples of memorable names can be found in the Mont Fleur scenarios set and many scenariobuilding workshops conclude with a dramatisation by participants, with the final scenarios being committed to film.
} 
As mentioned, rehearsals are close to scene construction ${ }^{28}$ (Hassabis \& Maguire, 2007) of people, places and objects - as in a scenario. When thinking about futures that have familiar components, the brain draws mainly upon episodic memory. Rehearsals can help with recall but unfamiliar future scene imagination relies on the brain to download external data (semantic memory). Many scenarios will contain such unfamiliar information and so are difficult to encode as a future memory. More, as van Mulokom et alia ( $p$ p cit) assert, familiar scenes are rated as more plausible and memorable than unfamiliar scenes. The latter are difficult to construct and to reconstruct. Analogously, in scenario building, the unfamiliar nature of much of the content of generic scenarios (e.g., global ones) contrasts with the familiar nature of sector specific scenarios for many participants within the sector. For research, this suggests a number of questions: Do participants accept a scenario set as more plausible if the content is very familiar? Are sector scenarios seen as easier to build and more plausible than generic ones? Are sector scenarios accepted more readily at the testing stage than generic ones?

Here, the research challenge is for scenario planners and cognitive scientists to work more closely with semantic memory and scene construction to get a better idea of the interplay between them. Business historians, who can tease out past scenes and incorporate them gently into future ones, may help them in this endeavor. The major impact of this research output is likely to be on the scenario building stage.

\section{Opportunity 5}

Related to the CESH work, other cognitive studies have much to offer in re-thinking the IL process. For instance, Miles et al (2014) found that mental imaginings were accompanied by physical actions when participants simulated good or bad scenarios, when viewed from a third party perspective (i.e., they could see themselves in the story):

"Guided by the assumption that imagined scenarios retain essential properties (e.g., spatial, temporal, perceptual, motoric) of the events they represent, neuroimaging and behavioral research has revealed considerable overlap in the operations (i.e., neural, cognitive) that support both mental simulation and actual behaviour." (Miles et al, 2013, p558)

If this is the case, then physical feelings could accompany the imagination of scenarios with positive or negative components, giving rise to several research questions: Are plausibility ratings by participants for scenarios with positive features higher than those scenarios containing more negative features? Do participants opt for more positive than negative features when building scenarios? If so, the latter may remain under-represented in both presence and detail in a scenario set. Again, co-joint research between scenario planners and cognitive scientists is required to tease out reactions to the positive and negative components within different scenarios so the design of a more balanced set is possible. Major impacts of this research output are likely to be on the scenario building and scenario testing stages.

\footnotetext{
${ }^{28}$ Scenarios derived their nomenclature from outlines of play and films, providing plot details and individual scenes on storyboards. Hermann Kahn is said to have adopted the term after Hollywood rejected it.
} 


\section{Vignette 1: Independent Caring Association}

Independent Caring (ICA) is an organisation specializing in aged care and located in a mature, western style economy. Founded over 50 years ago, it operates a broad range of residential and homecare services for the elderly with particular skills in dementia and palliative care. All its services are fully accredited by the relevant agencies and, frequently, it surpasses the criteria of the regularity audits to which it is subjected. Hence, it has won many prizes for the high level of its care and for many innovations therein.

Recently, scenario planning was used in preparation for the next phase of its seven-year strategic plan. The organisation was not familiar with the techniques involved and employed external consultants to facilitate the process. A classic 'intuitive logics' process (the stages of which are displayed in Figures $1 \& 2$ and denoted in italics below), coupled with a Delphi study, was deployed over a six-month period. These engaged the Board, the senior management team, an army of operational managers and key external stakeholders. Senior management had many years of experience within the sector, with few experiential reference points beyond it. The style could be described as 'competent, conservative and more authoritarian than consultative'. In the previous year, the consultants had completed a scenario project in the same sector and in the same country for an organisation with a pro-active management style (PAMS Association), populated by entrepreneurial senior management with plenty of experience beyond their sector.

In the project scoping exercise, the CEO chose the time horizon, geographic boundary, the business area and the list of internal and external people for a data collection interview. It became apparent from the ICA interview data and much dialogue internally that the cognition of some senior managers in ICA might find the task of future thinking 'challenging'. Hence, using the suggestions for 'cognitive rehearsals' from cognitive science research, a 'futures rehearsal' was conducted at the start of the scenario-building workshop. This 'familiarisation' with a 'far fetched', intangible process was deemed necessary to: a) overcome their initial resistance to thinking beyond 5 years and b) to establish their comfort in working and thinking in that deep future space and the legitimacy of doing so. It consisted of the consideration of a contemporary broadsheet newspaper story on wage differentials between the 'Baby Boomers' and 'Generations Y' and 'Generation Z'. Participants were asked to think through the implications of this disparity for broader society in their country over a 15 -year period. Despite the familiarity of each participant with each other, the initial dialogue was slow and discontinuous, with much prompting from consultants. This stuttering phase was followed quickly with a phase of sustained future thinking. Some of the thinking here could be described as illogical and implausible while other parts were logical and consistent, as participants grappled with future thinking for the first time. Though, both consultants ${ }^{29}$ judged that overall, their thinking was for a much shorter horizon than the 15-year target. After this rehearsal, the scenario building workshop continued and was followed by the stages of scenario writing, scenario testing, refining and a scenario to strategy workshop as per a conventional IL process.

The consultants compared the structure and content of the first draft output from the scenario writing stages of the two projects, the PAMS (without the rehearsal) and the ICA (with the rehearsal) scenario workshops. They found the PAMS set to be more creative in content and more extensive in time-horizon thinking. The ICA set was limited in its horizon, relying more on extensions of the 'here and now' and only partially on future technologies like Robotics, Artificial Intelligence and Driverless Cars for the Aged. This finding might be due to the markedly different experiences and styles of the senior management teams.

This was a 'crude' addition of 'future rehearsals' to the IL process and the result is inconclusive. Certainly, the rehearsal helped the ICA team to ease into their future thinking and feel more comfortable working in deeper futures than before and to deliver a set of scenarios that were 'acceptable' within their 'frame'. Once legitimacy of working in deep future space was established, a full engagement followed as evidenced by the ease of ideasgeneration and the appetite for more global thinking.

Clearly, such a 'future rehearsal' addition requires refinement of measurements and much more controlled experimentation than was possible in this exercise.

\section{Opportunity 6}

Scenario planning can be data hungry, especially in the IL process, where building large data workbooks in preparation for a scenario-building workshop is an integrated part. This workbook needs to be populated from well-informed and accurate data sources. Psychologists (Lewandowsky et alia, 2011) have shown that misinformation

29 Two consultants facilitated this exercise: one with a background in management and one with a background in psychology. 
is extensive in a modern consumer society and that its correction is neither immediate nor sustained. Misinformation has many sources e.g., rumour, media, political influence and even genuine misunderstanding or misinterpretation of a factual account.

Scenario planners can and do adopt the right sort of filters in data collection e.g. checking whether the evidence is compatible, cohesive, credibly sourced and believed widely for these reasons and not because a data entry is an oft-repeated urban myth. If the checking is not done and the data is riddled with error or myth, then what the scenario participants read becomes locked into the brain as 'fact'. This is a very difficult to remove, even after many retractions e.g., Listerine made false claims for 50 years in the USA that it helped reduce the severity of colds and sore throats; even after it was forced to retract through corrective advertising ( $\$ 10 \mathrm{~m}$ budget), at least $42 \%$ of consumers still believed that the product was promoted as an effective cold remedy. What people know about the past constrains what they can imagine about the future. Indeed, research on false memory (e.g., Gerrie et alia, 2006) shows that the brain fills in gaps in episodic memory with information from any source that it might conjure up; even if that is entirely inaccurate.

Co-joint research here might involve a thorough analysis of the data workbooks for a sample of scenario projects; an audit of the filters used in those projects; the extent to which the workbooks informed the eventual scenarios and an audit of the scenarios themselves. Basically, does misinformation play a key role in scenario building? This impact will be largely upon the data collection stage.

\subsection{Summary and Conclusion}

The purpose of this paper is to explore how the intuitive logics, SP process might be improved by borrowing from an adjacent field of scholarship. In so doing, the overall creative process and its individual stages might be enhanced. The potential impact of the cognitive sciences has been illustrated on several stages of the SP process from careful attention to individual cognition during the project scoping and the diagnosis stage, when different actors might perceive the problem and scope in different ways; careful sample design in individual interviewing during data collection and scenario building, that balances general prospecting with episodic recall; on the age balance in both interviewing and in participant attendance during the scenario building and scenario to strategy workshops; on the design of a 'futures cognitive interview' linked to scenario rehearsals in scenario building; and on the need to focus more on the negative components of the scenarios in scenario building; and on the emotive linkages to physical reaction in the scenario building and scenario testing stages. The impacts on the key stages of the IL process are illustrated in Figure 2 below: 
The scenario building stage attracts the most potential for innovation. Given the importance of this stage to the SP Process, cognate contributions could be vital in fortifying that human process with the application of science. More, given that the prior stages from data collection to the establishment of key issues can be backed up strongly with good social science in research methodology, the development of the scenario building stage should enhance creativity, detail and vividness in scenarios and so protect scenario planning from being invoked as part of any cognitive 'failure of imagination' or 'failure in the art of re-thinking' (see Patel, op cit) ${ }^{30}$.

Despite the potential gains for scenario planning from the cognitive sciences in terms of prospective thinking, there exist a number of potential weaknesses. As Gilbert and Wilson (2007) note, errors within the brain's mechanism of prospection can lead to it making faulty simulations of future events. For instance, future simulations suffer from a) inaccurate memories of the past that cause the future to be blurred; b) a focus on the main features of the future imagined state and an omission of the 'inessential features' of it; c) a condensed form of a future state e.g., a few select moments rather than a fully detailed exposition; d) an assumption that the contextual factors acting upon today's state will be the same as those acting on the future state. As they say:

\footnotetext{
"The cortex attempts to trick the rest of the brain by impersonating a sensory system. It simulates future events to find out what the subcortical structures know, but try as it might, the cortex cannot generate simulations that have all the richness and reality of genuine perceptions."
}

(Gilbert and Wilson, 2007, p1354)

This is important for scenario planning for number of reasons. First, research shows that people tend to emphasise atypical events (e.g., more extreme or negative ones) when forming future simulations of similar events, because those events are more memorable (Morewedge et alia, 2005). Future scenarios may well be tainted by such extremes because scenario builders have used this 'wrong' past in the process of simulation. Second, because inessential features are 'missing' from many future simulations, the future scenarios may be contain more generalities than specifics. This might be reinforced with an older age group (see above). Third, future specificity may suffer again because people tend to emphasise the detail in the early periods more clearly than later future periods. If the scenario project contains a study of deep futures (say over 20 years), the greater the likelihood that detail will be missing as the brain performs its trickery. Finally, many scenario participants are guilty of thinking and working in the 'here and now', under the influence of a particular context. Clearly, it is unlikely that that context will be repeated exactly in the future and so the brain may need educating into thinking outside prevailing parameters, say through rehearsals, before it begins its formal scenario building.

This paper has its limitations. These include a degree of speculation about direct linkages from brain research on individuals per se and how individuals behave in scenario group workshops when under the spotlight of their peers and, probably, senior line managers. Further, in the absence of a substantive body of empirical evidence $^{31}$, it is difficult to say whether the brain related findings would improve the

\footnotetext{
${ }^{30}$ Calcified mental routines can cause fault lines e.g., in US domestic security after the $9 / 11$ crisis and in the Enron bankruptcy.

31 Significantly, recent research (see Laureiro-Martinez, 2014) has found positive links between planning and the brain's central control capability to a person's ability to generate routines and
} 
IL process, as suggested herein. The small but 'live' test illustrated in the vignette was practically focused and had useful unifying and legitimising benefits, but was a far cry from a controlled scientific experiment. Indeed, much of the extant brain research deals with immediate futures like the imagination of events tomorrow. SP deals with deep futures, far removed from the present. It might be a leap of faith to think that those results would hold over such a long period when the brain has difficulty with imagining the next day's play. Finally, not all scenario projects are the same.

Differences in context and culture mean that each IL process has to be adapted to suit a particular phenomenon. Conducting scientific experiments with such a moveable feast could be plagued by its own difficulties of control and replication, making the building of a knowledge base tricky. But, if we don't start, we shall never know.

To enable this interdisciplinary marriage, scenario planners might work closer together with cognitive psychologists, especially in the behavioural neuroscience area. This might begin with a resource audit of what is known in each domain, what is in the research and development 'laboratory' and what could be known if research agendas were re-examined. Clearly, from the brief review above and suggested opportunities, injections into scenario planning could help us better understand the IL approach from a interdisciplinary perspective. However, successful interdisciplinary research projects usually contain symmetric benefits. Hence the question is posed: why would scenario planning interest cognitive scientists? For neuroscience, Powell (op cit) notes:

“... strategy researchers who want to conduct neuroscience must show neuroscientists that strategy brings something new and interesting to their field - that is that strategic management gives neuroscientists access to social science expertise and research insights that they cannot get from economics, law, politics, or marketing. If strategy offers nothing new to neuroscience, then the future of neuroscience is severely limited." (Powell, op cit, p1492)

The close proximity of scenario planning to the cognitive science research approach of remembering the past and imagining the future suggests that a mutually beneficial research agenda might be developed. First, scenario planning provides access to group based activity of imagining the future that complements the individual activity contained in much of the neuroscience research. The study of the contrast between group and individual 'thinking' characteristics should enhance both neuroscience and scenario process research. Second, although scenario building groups may have the temporary characteristics of a liminal "communitas', they are charged with a specific task - that of future thinking and scenario production, as part of a process rather than as a singular experimental design. Again, contrasts between individual thinking on a volunteer basis and group thinking when the process is formal should yield results that are useful for effective project or process design. Third, a crucial component of scenario planning is its need and ability to help participants imagine broader horizons through the employment of multiple perspectives. By allowing individuals to pursue mental time travel, episodic memory contributes to the process of creating many perspectives and, although there are limits e.g., in repeat imaginations, scenario workshops make a rich laboratory for cognitive scientists to explore contrasts in the time travel for both individuals and groups. For instance, under what conditions can breadth of vision be improved for both?

performance in innovation decision taking. So, there is hope for brain research in scenario planning. 
Fourth, groups in a scenario planning workshop can be adjusted for key cognitive design variables like age and familiarity with future content (as might be the case in sector studies-see above) to explore differences in scenario outcomes that might happen as a result of scaffolding the future on episodic memory rather than on semantic memory, or on a combination of the two. Finally, this co-joint research challenge might be linked to the softer psychological analysis of narrative (using the letters of patients) in future imaginings in health research (Sools et alia, 2015) with the harder neuroscience of social cognition and so explore the mutual benefits for patients; a place where scenario planning, with its mental representations of future scenes, might make a real difference.

Scenario planning and the cognitive sciences share a common interest in exploring the past and relating it to imaginings of the future. A creative co-joint research agenda will benefit both domains while rendering the mental underpinnings of 'prospective thinking' more transparent.

\section{References}

E. Abrahamson, Managerial fads and fashions: The diffusion and rejection of innovations, Academy of management review, 16 (1991) 586-612.

D.R. Addis, L. Pan, M.A. Vu, N. Laiser, D.L. Schacter, Constructive episodic simulation of the future and the past: Distinct subsystems of a core brain network mediate imagining and remembering, Neuropsychologia, 47 (2009) 2222-2238.

D.R. Addis, A.T. Wong, D.L. Schacter, Age-related changes in the episodic simulation of future events, Psychological Science, 19 (2008) 33-41.

J.R. Anderson, L.J. Schooler, Reflections of the environment in memory, Psychological Science, 2 (1991) 396-408.

R. J. Anderson, Imagining novel futures: The roles of event plausibility and familiarity, Memory, 20 (2012) 443-451. doi:10.1080/09658211.2012.677450.

A. Bandura, Social cognitive theory: An agentic perspective, annual review of Psychology, 52 (2001) 1-26.

P. S. Barr, Adapting to unfamiliar environmental events: a look at the evolution of interpretation and its role in strategic change, Organization Science, 9, (1998) 644-69. 
M.R. Bennett, P.M.S. Hacker, Philosophical foundations of neuroscience, Blackwell Publishing: Malden, MA. 2003

D. Boje, Storytelling organizations. Sage Publications, London (2008).

D. Boje, Consulting and change in storytelling organizations, J. Organ. Chang. Manag. 4 (1991) 7-17.

A. Botzung, E. Denkova, L. Manning, Experiencing past and future personal events: Functional neuorimaging evidence on the neural bases of mental time travel, Brain and Cognition, 66 (2008) 202-212.

G. Bowman, B.R. MacKay, S. Masrani, P. McKiernan, Storytelling and the scenario process: Understanding success and failure. Technological Forecasting \& Social Change, 80 (2013) 735-748.

R. Bradfield, J. Derbyshire, G. Wright, The critical role of history in scenario thinking: Augmenting causal analysis within the intuitive logics scenario development methodology. Futures, 77 (2016) 56-66.

R. Bradfield, G. Wright, G. Burt, G. Cairns, K. van der Heijden, The origins and evolution of scenario techniques in long range planning. Futures, 37 (8) (2005) 795812.

J.S. Carroll, The effect of imagining an event on expectations for the event: An interpretation in terms of the availability heuristic, Journal of Experimental Social , 14 (1978) 88-96.

I. Coleville, R.H. Waterman, K. Weick, Organizing and the search for excellence: Making sense of times in theory and practice. Organization, 6 (1999) 129-148.

H. Courtney, J. Kirkland, P. Viguerie, Strategy Under Uncertainty, Harvard Business Review, Nov/Dec 75(6) 1997 66-79.

S. Cummings, U. Daellenbach, A guide to the future of strategy? The history of long range planning, Long Range Planning, 42(2) (2009) 234-263.

R. L. Daft, K. E. Weick, Toward a model of organizations as interpretation systems. Academy of Management Review, 9 (1984) 284-95.

A. Dimoka, What does the brain tell us about trust and distrust? Evidence from a functional neuroimaging study, MIS Quart., 34(2) (2010) 373-396.

A. Dimoka, P.A. Pavlou, F.D. Davies. NeuroIS: The potential of cognitive neuroscience for IS Research, Information Systems Research, 22(4) (2011) 687-702.

J.F. Dovidio, A.R. Pearson, P. Orr. Social psychology and neuroscience: Strange bedfellows or a healthy marriage? Group Processes and Intergroup Relations, 11 (2008) 247-263. 
K. D. Elsbach, P. S. Barr, A. B. Hargadon, Identifying situated cognition in organizations, Organization Science, 16 (2005) 422-33.

Z. Eser, F.B. Isin, M. Tolon. Perceptions of marketing academics, neurologists and marketing professionals about neuromarketing, Journal of Marketing Management, July 27(7\&8) (2011) 854-868.

D. Ferrante, V. Girotto, M. Stragà, C. Walsh, Improving the past and the future: A temporal asymmetry in hypothetical thinking, Journal of Experimental Psychology: General, 142 (2013) 23.

R. P. Fisher, R. E. Geiselman, Memory enhancing techniques for investigative interviewing: The cognitive interview, Springfield, IL: Charles C. Thomas Books, 1992.

S. T. Fiske, S. E. Taylor, Social Cognition. New York: Random House, 1984.

H. Gardner, Changing Minds. Harvard Business School Press, Boston, MA., 2000.

R. E. Geiselman, R. P. Fisher, D. P. MacKinnon, H. L. Holland, Eyewitness memory enhancement in the police interview: Cognitive retrieval mnemonics versus hypnosis. Journal of Applied Psychology, 70(2) (1985) 401-412.

M. P. Gerrie, L. E. Belcher, M. Garry, Mind the gap: False memories for missing aspects of an event. Applied Cognitive Psychology, 20 (2006) 689-696.

D.T. Gilbert, T.D. Wilson, Prospection: Experiencing the Future, Science, 317 (2007) 1351-1354.

J. Gill, S. Whittle, Management by panacea: Accounting for transience. Journal of Management Studies, 30 (1993) 281-295.

P. W. Glimcher, Foundations of neuroeconomic analysis. Oxford, England: Oxford University Press, (2011).

D. A. Gioia, K. Chittipeddi, Sensemaking and sensegiving in strategic change initiation. Strategic Management Journal, 12 (1991)433.

D. Hassabis, E.A. Maguire. Deconstructing episodic memory with construction: Trends in cognitive sciences, 11 (2007) 299-306.

D. Hassabis, R.N. Spreng, A.A. Rusu, C.A. Robbins, R.A. Mar, D.L. Schacter. Imagine all the people: How the brain creates and uses personality models to predict behavior, Cerebral Cortex, August 24(8) (2013) 1979-87

G.P. Hodgkinson, The cognitive analysis of competitive structures: A review and critique, Human Relations, 50 (1997) 625-54.

G.P. Hodgkinson, M.P. Healey, Cognition in organisations: Annual Review of Psychology, January 59 (2008) 387-417 
G.P. Hodgkinson, G. Wright, Confronting strategic inertia in a top management team: Learning from failure, Organization Studies, 23 (2002) 949-977.

A. S. Huff, Industry influences on strategy reformulation, Strategic Management Journal, 3 (1982) 119-31.

D.H. Ingvar, Hyperfrontal distribution of the cerebral grey matter flow in resting Wakefulness: On the functional anatomy of the conscious state, Acta Neurologica Scandinavica, 60 (1979) 12-25.

D.H. Ingvar, Memory of the Future: An essay on the temporal organization of conscious awareness, Hum. Neurobiol. 4(3) (1985) 127-136.

M. Irish, D.R. Addis, J.R. Hodges, O. Piguet, Considering the role of semantic memory in episodic future thinking: Evidence from semantic dementia, Brain, 135 (2012) 2178-2191.

G. Isamella, J.A. Mazzon, A. Dimoka, Culture differences, difficulties and challenges of the neurophysiological methods in marketing research, Journal of International Consumer Marketing, 27 (2015) 346-363.

O. Janssen, Innovative behaviour and job involvement at the price of conflict and less satisfactory relations with co-workers, Journal of Occupational and Organizational Psychology, 76 (2003) 347-364.

O. Janssen, How fairness perceptions make innovative behavior more or less stressful, Journal of Organizational Behavior, 25 (2004) 201-215.

M. Jefferson, Shell scenarios: what really happened in the 1970s and what may be learned for current world prospects. Technological Forecasting \& Social Change, 79(1) (2012) 186-197.

H. Kahn, On thermonuclear war, Princeton University Press, Princeton, NJ, (1960).

H. Kahn, Thinking about the unthinkable, Horizon Press, New York, 1962.

S. Kaplan, Cognition, capabilities and incentives: Assessing firm response to the fibre optic revolution. Academy of Management Journal, 51(4) (2008a) 672-695.

S. Kaplan, Framing contests: Strategy making under uncertainty. Organisational Science, 19(5) (2008b) 729-752.

S. Kaplan, Research in cognition and strategy: Reflections on two decades of progress and a look into the future, Journal of management studies, 48(3) (2011) 665-695.

S. Klein, Making the case that episodic recollection is attributable to operations occurring at retrieval rather than to content stored in a dedicated subsystem of longterm memory, Frontiers in Behavioural Neurology, Feb 1 (2013) PMC3561741. 
S. B. Klein, T. E. Robertson, A. W. Delton, M. L. Lax, Familiarity and personal experience as mediators of recall when planning for future contingencies, Journal of Experimental Psychology: Learning, memory and cognition, 38(1) (2012) 240-245. doi:10.1037/a0025200.

A. Kleiner, (1996). The age of heretics: Heroes, outlaws, and the forerunners of corporate change. First ed. Currency-Doubleday, New York, 1996.

S. Kuhn, E. Strelow, J. Gallinat, Multiple 'buy buttons' in the brain: Forecasting chocolate sales at point-of-sale based on functional brain activation using fMRI, Neurolmage, 136 (2016) 122-128.

D. Laureiro-Martínez, N. Canessa, S. Brusoni, M. Zollo, T. Hare, F. Alemanno, S.F. Cappa, Frontopolar cortex and decision-making efficiency: comparing brain activity of experts with different professional background during an exploration-exploitation task, Frontiers in Human Neuroscience, 7 (2014) 1-10

D. Laureiro-Martinez, Cognitive control capabilities, routinization propensity, and decision-making performance, Organizational Science, 25(4) (2014) 1111-1133

D. Laureiro-Martínez, S. Brusoni, N. Canessa, M. Zollo, Understanding the exploration-exploitation dilemma: an fMRI study of attention control and decisionmaking performance, Strategic Management Journal, 36(3) (2015a) 319-338

D. Laureiro-Martínez, V. Venkatraman, S. Cappa, M. Zollo, S. Brusoni, Cognitive neurosciences and strategic management: Challenges and opportunities in tying the knot, Advances in Strategic Management: Cognition and Strategy, 32 (2015b) 351370

S. Lewandowsky, U.K.H Ecker, C.M. Seifert, N. Schwarz, J. Cook, Misinformation and its correction: Continued influence and successful debiasing, Psychological Science, 13(3) (2012) 106-131.

L.P. Livingstone, D.L. Nelson, S.H. Barr, Person-environment fit and creativity: An examination of supply-value and demand-ability versions of fit, Journal of Management, 23 (1997) 119-146.

N.K. Logothetis, What we can do and what we cannot do with fMRI, Nature, 453 (7197) (2008) 869-878.

J.L Lusk, J.M. Crespi, J.B.C. Cherry, B.R. McFadden, L.E. Martin, A.S. Bruce, An fMRI investigation of consumer choice regarding controversial food technologies, Food quality and preference, 40 (2015) 209-220.

D. Kahneman, A. Tversky, On the psychology of prediction, Psychological Review, 80(4) July (1973) 237-251

D. MacKay, P. McKiernan, Strategic sense giving from the periphery: What top management does not hear, University of Strathclyde working paper, 2016 
K. P. Madore, D. L. Schacter, Remembering the past and imagining the future: Selective effects of an episodic specificity induction on detail generation, The Quarterly Journal of Experimental Psychology, 69(2) (2016) 285-298, DOI: 10.1080/17470218.2014.999097.

K.P. Madore, B. Gaesser, D.L. Schacter, Constructive episodic simulation: Dissociable effects of a specificity induction on remembering, imagining and describing in young and older adults, Journal of experimental psychology: Learning, Memory and Cognition, 40 (2014) 609.

J. G. March, H. A. Simon, Organizations. New York: Wiley, (1958).

S.M. McClure, J. Li, D. Tomlin, K.S.Cypert, L.M. Montague, P.R. Montague, Neural correlates of behavioural preference for culturally familiar drinks, Neron, 44(2) (2004) 379-387.

J. McGee, H. Thomas, Strategic groups: theory, research and taxonomy. Strategic Management Journal, 7 (1986) 141.

P. McKiernan, Scenario planning, In: Wiley Encyclopedia of Management, IIIrd Edition, Wiley, Chichester, (2012).

V.C. McLelland, A.L. Devitt, D.L. Schacter, D.R. Addis, Making the future memorable: The phenomenology of remembered future events, Memory, (2014) DOI: 10.1080/09658211.2014.972960.

F. J. Milliken, Perceiving and interpreting environmental-change: An examination of college administrators interpretation of changing demographics. Academy of Management Journal, 33 (1990).42-63.

L.K Miles, B.M Christian, N. Masilamani, L.Volpi \& C. Neil Macrae, Not so close encounters of the third kind: Visual perspective and imagined social interaction, Social Psychology and Personality Science, Nov 8 5(5) (2014) 558-565.

E. Miron, M. Erez, E. Naveh, Do personal characteristics and cultural values that promote innovation, quality, and efficiency compete or complement each other? Journal of Organizational Behavior, 25 (2004) 175-199.

C.K. Morewedge, D.T. Gilbert, T.D. Wilson, The least likely of times - How remembering the past biases forecasts of the future, Psychological Science, 16 (2005) 626-630.

A. Patel, Gaining insight: Re-thinking at the edge, Technological Forecasting \& Social Change, 107 (2016) 141-153. 
S. Pighin, R.M. Byrne, D. Ferrante, M. Gonzalez, V. Girotto, Counterfactual thoughts about experienced, observed and narrated events, Thinking \& Reasoning, 17 (2011) 197-211.

H. Poincare, The foundations of science, Lancaster PA: Science Press, 1913.

J. F. Porac, H. Thomas, C. Baden-Fuller, Competitive groups as cognitive communities: The case of Scottish knitwear manufacturers. Journal of Management Studies, 26 (1989) 397-416.

T.C. Powell, Neuroscience, Strategic Management Journal, 32(13) (Dec 2011) 14841499.

C. J. Price, K. J. Friston, Functional ontologies for cognition: The systematic definition of structure and function. Cognitive Neuropsychology 22(3/4) (2005) 262275.

C.J. Rathbone, M.A. Conway, C.J. Moulin, Remembering and imagining: The role of the self, Consciousness and Cognition, 20 (2011) 1175-1182.

D. Raune, A. MacLeod, E.A. Holmes, The simulation heuristic and visual imagery in pessimism for future negative events in anxiety, Clinical Psychology \& Psychotherapy, 12 (2005) 313-325.

P.G. Rendell, P.E. Bailey, J.D. Henry, L.H. Phillips, S. Gaskin, M. Kliegel, Older adults have greater difficulty imagining future rather than atemporal experiences, Psychology and Aging, 27 (2012) 1089.

N.J. Roese, J.M. Olson, Outcome controllability and counterfactual thinking, Personality and Social Psychology Bulletin, 21 (1995) 620-628,

L. Rouleau, Micro-practices of strategic sensemaking and sensegiving: How middle managers interpret and sell change every day, Journal of Management Studies, 42 (2005). 1413-41.

A. Rustichini, Neuroeconomics: Present and future, Games Economic Behaviour, 52 (2005) 201-212.

L.J. Sanna, Defensive pessimism, optimism, and simulating alternatives: Some ups and downs or prefactual and counterfactual thinking, Journal of Personality and Social Psychology, 71(5) (1996) 1017-1020.

D.L. Schacter, The seven sins of memory: Insights from psychological and cognitive neuroscience, American Psychologist, 54(3) (1999) 182-203.

D.L. Schacter, D.R. Addis, The cognitive neuroscience of constructive memory: Remembering the past and imagining the future, Philosophical transactions of the Royal Society of London B: Biological Sciences, 362 (2007) 773-786. 
D.L. Schacter, D.R. Addis, R.L. Buckner, Remembering the past to imagine the future: The prospective brain, Nature reviews neuroscience, 8 (2007) 657-661.

D.L. Schacter, D.R. Addis, R.L. Buckner, Episodic simulation of future events, Annals of the New York Academy of Sciences, 1124 (2008) 39-60.

D.L. Schacter, B. Gaesser, D.R. Addis, Rememerbing the past and imagining the future in the elderley, Gerontology, 59 (2013) 143-151, DOI:10.1159/000342198.

D.L. Schacter, R.G. Benoit, F. De Brigard, K.K. Szpunar, Episodic future thinking and episodic counterfactual thinking: Intersections between memory and decisions, Neurobiology of learning and memory, 117 (2015) 14-21.

Schacter D.L. \& Madore K.P. (2015: in press). Remembering the past and imagining the future: Identifying and enhancing the contribution of episodic memory.

P. Schwartz, The art of the long view, New York: Doubleday, 1991.

P.J.H. Schoemaker, Scenario planning: A tool for strategic thinking. Sloan Management Review, 23 (2) (1995) 25-34.

A.M. Sools, T. Tromp, J.H. Mooren, Mapping letters of the future, Exploring narrative processes of mapping the future, Journal of Health Psychology, 20/3 (2015) 350-364.

J. C. Spender, Industry recipes: An enquiry into the nature and sources of managerial judgement. Basil Blackwell, Oxford, 1989.

T. Suddendorf, M.C. Corballis, Mental time travel and the evolution of the human mind, Genetic, Social and General Psychology Monographs, 123 (1997) 133-167.

K.M. Sutcliffe, What executives notice: Accurate perceptions in top management teams. Academy of Management Journal, 37 (1994) 1360.

J. Suomala, L. Palokangas, S. Leminen, M. Westerlund, J. Heinonen, J. Numminen, Neuromarketing: Understanding customer's subconscious responses to marketing. Technology Innovation Management Review, 2(12) (2012) 12-21.

K.K. Szpunar, D.R. Addis, V.C. McLelland, D.L. Schacter, Memories of the future: New insights into the adaptive value of episodic memory, Frontiers in Behavioral Neuroscience, 7 (2013) 47.

K.K. Szpunar, K.B. McDermott, Episodic future thought and its relation to remembering: Evidence from ratings of subjective experience, Consciousness and Cognition, 17 (2008) 330-334.

K.K. Szpunar, D.L. Schacter, Get real: Effects of repeated simulation and emotion on the perceived plausibility of future experiences, Journal of Experimental Psychology: General, 142 (2013) 323. 
K.K. Szpunar, R.N. Spreng, D.L. Schacter, A taxonomy of prospection: Introducing an organizational framework for future-oriented cognition, Proceedings of the National Academy of Sciences, 111 (2014) 18414-18421.

E. Tulving, Elements of episodic memory, Oxford University Press, (1985).

K. Van der Heijden, Scenarios: The art of strategic conversation, Chichester: John Wiley \& Sons, 1996.

N. Van Hoeck, N. Ma, L. Ampe, K. Baetens, M. Vandekerckhove, F. Van Overwalle, Counterfactual thinking: an fMRI study on changing the past for a better future, Social cognitive and affective neuroscience, (2012) nss031 and SCAN (2013) 8, 556564.

V. Van Mulukom, D.L. Schacter, M.C. Corballis, D.R. Addis, The degree of disparteness of event details modulates future simulation construction, plausibility and recall, The quarterly journal of experimental psychology, 69(2) (2016) 234-242 DOI: $10.1080 / 17470218.2015 .1051559$.

P. Wack, Scenarios: Uncharted waters ahead. Harvard Business Review 63 (5) (1985a) 73-89.

P. Wack, Scenarios: Shooting the rapids. Harvard Business Review 63 (6) (1985b) 139-150.

D.A.Waldman, P.A Balthazard, S.J Peterson, Social cognitive science and leadership, The leadership quarterly, 22 (2011) 1092-1106.

J. P. Walsh, Managerial and organizational cognition: Notes from a trip down memory lane, Organization science, 6, (1995) 280-321.

J. P. Walsh, L. Fahey, The role of negotiated belief structures in strategy making, Journal of management, 12 (1986) 325-38.

R.W. Weisberg, Creativity: Beyond the myth of genius, New York, Freeman, 1993.

J. Zhou, J.M George, When job dissatisfaction leads to creativity, Academy of Management Journal, 44(4) (2001) 682-696.

A. Wilkinson, R. Kupers, Living in the futures. Harvard Business Review 91(5) (2013) 118-127.

I. Wilson, Mental maps of the future: An intuitive logics approach to scenarios, Chapter 5 in L. Fahey \& R.M. Randall (Eds.), Learning from the future: Competitive foresight scenarios, John Wiley Inc., New York, (1998). 


\begin{tabular}{|l|l|}
\hline \multicolumn{1}{|c|}{ Stage } & \multicolumn{1}{|c|}{ Content } \\
\hline Project Scoping \& Diagnosis & $\begin{array}{l}\text { Establishing the topic of focus for the future study and } \\
\text { deciding upon a future horizon and geographic scope }\end{array}$ \\
\hline Data Collection & $\begin{array}{l}\text { Collecting data from multiple sources e.g., personal or } \\
\text { group interviews, Delphi studies, extant publications etc. }\end{array}$ \\
\hline Data Base & Building a database from the output of the previous step \\
\hline Analysis & $\begin{array}{l}\text { Analysing the data and checking for type 1 and type2 } \\
\text { errors }\end{array}$ \\
\hline Synthesis & Collating the data into themes \\
\hline Key Issues & $\begin{array}{l}\text { Identifying key issues in the data that may need further } \\
\text { investigation, say, by experts }\end{array}$ \\
\hline Exploration & $\begin{array}{l}\text { Exploring the data set ready for drivers of future change } \\
\text { and how these shape the future context }\end{array}$ \\
\hline Scenario Building & $\begin{array}{l}\text { Building the scenarios from the drivers identified in the } \\
\text { data set in a workshop setting using a structured or } \\
\text { semi-structured method }\end{array}$ \\
\hline Writing & Writing the first draft of the scenarios \\
\hline Testing & $\begin{array}{l}\text { Testing the first draft scenarios for, for example, } \\
\text { plausibility, internal consistency, surprise, gestalt }\end{array}$ \\
\hline Refining & $\begin{array}{l}\text { Producing a further series of drafts of the scenarios as a } \\
\text { result of the tests above and feedback from the builders }\end{array}$ \\
\hline Scenarios to Strategy & $\begin{array}{l}\text { Employing the final draft of the scenarios to inform } \\
\text { strategic conversation and strategy development }\end{array}$ \\
\hline
\end{tabular}

TABLE 1: Stages of the Intuitive Logics Process

(Noted, there is some circularity in the stages and not all stages are included in any one process) 


\begin{tabular}{|c|c|}
\hline Item & Definition \\
\hline Prospective Thinking & Contemplation of future events that need not be personal \\
\hline Pre Factual Thinking & Pre outcome simulations \\
\hline Future Rehearsals & $\begin{array}{l}\text { Mental images of people, places and objects and how they } \\
\text { form stage settings of future imaginings }\end{array}$ \\
\hline Foresight & $\begin{array}{l}\text { A person's ability to guide their actions and simulate the } \\
\text { outcomes of them and of others in advance }\end{array}$ \\
\hline Neuroscience & Scientific study of the nervous system \\
\hline Cognitive Psychology & $\begin{array}{l}\text { Scientific study of mental processes and their role in } \\
\text { memory, language, thinking, feeling, and behaving. }\end{array}$ \\
\hline Scenario Planning ${ }^{32}$ & $\begin{array}{l}\text { A futures process that combines the creation of several } \\
\text { stories of plausible futures with the strategic responses } \\
\text { required to deal with them. }\end{array}$ \\
\hline Intuitive Logics (IL) ${ }^{33}$ & $\begin{array}{l}\text { A scenario process that combines the intuition of the most } \\
\text { informed actors within a logical, formal, and structured } \\
\text { approach }\end{array}$ \\
\hline Intuition & An instinct or a sixth sense; knowing without evidence \\
\hline $\begin{array}{l}\text { Episodic Future } \\
\text { Thinking }\end{array}$ & Imagining an episode that might occur in a person's future \\
\hline $\begin{array}{l}\text { Counterfactual } \\
\text { Thinking }\end{array}$ & $\begin{array}{l}\text { Imagining of alternative outcomes to those that actually } \\
\text { happened that need not be personal }\end{array}$ \\
\hline
\end{tabular}

TABLE 2

\footnotetext{
${ }^{32}$ Adapted from McKiernan, 2012

${ }^{33}$ Adapted from Wilson, 1998

${ }^{34}$ Adapted from Schacter et alia, 2015

${ }^{35}$ Adapted from Schacter et alia, 2015
} 


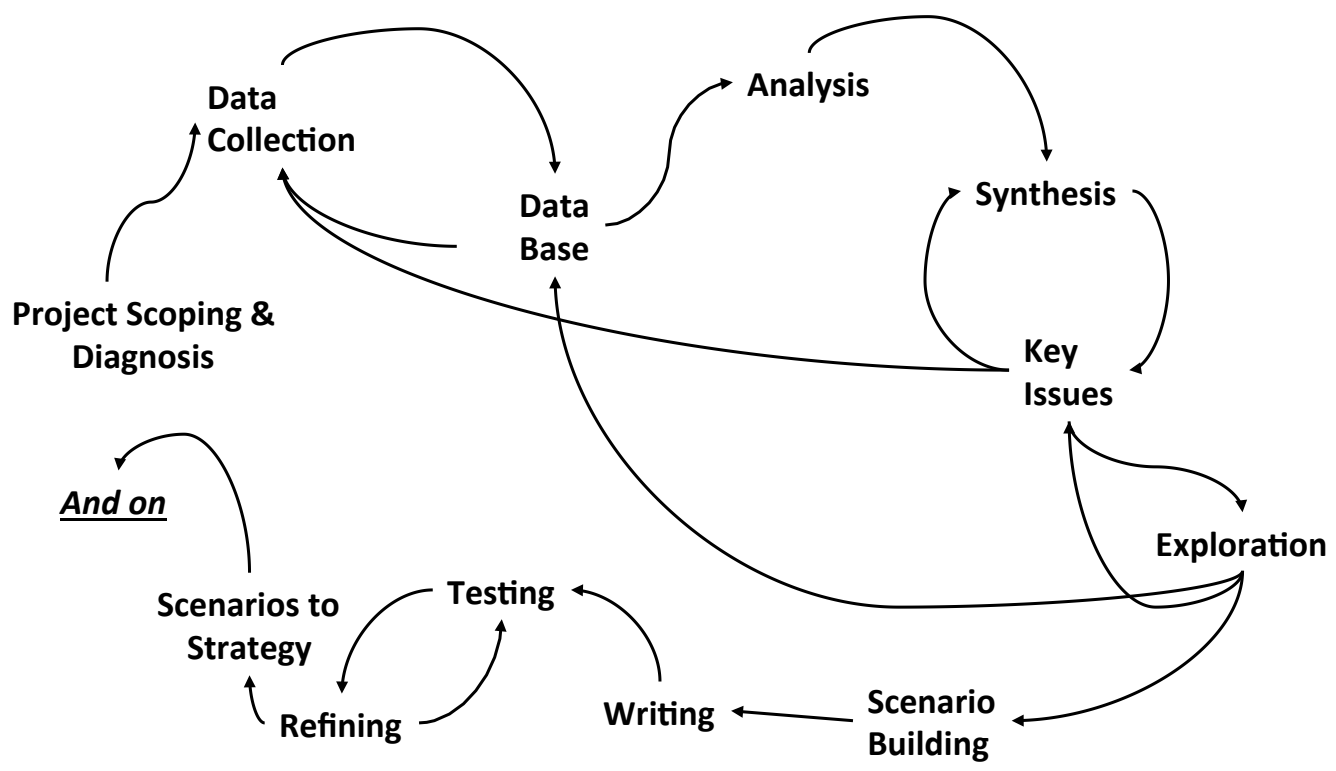

FIGURE 1 


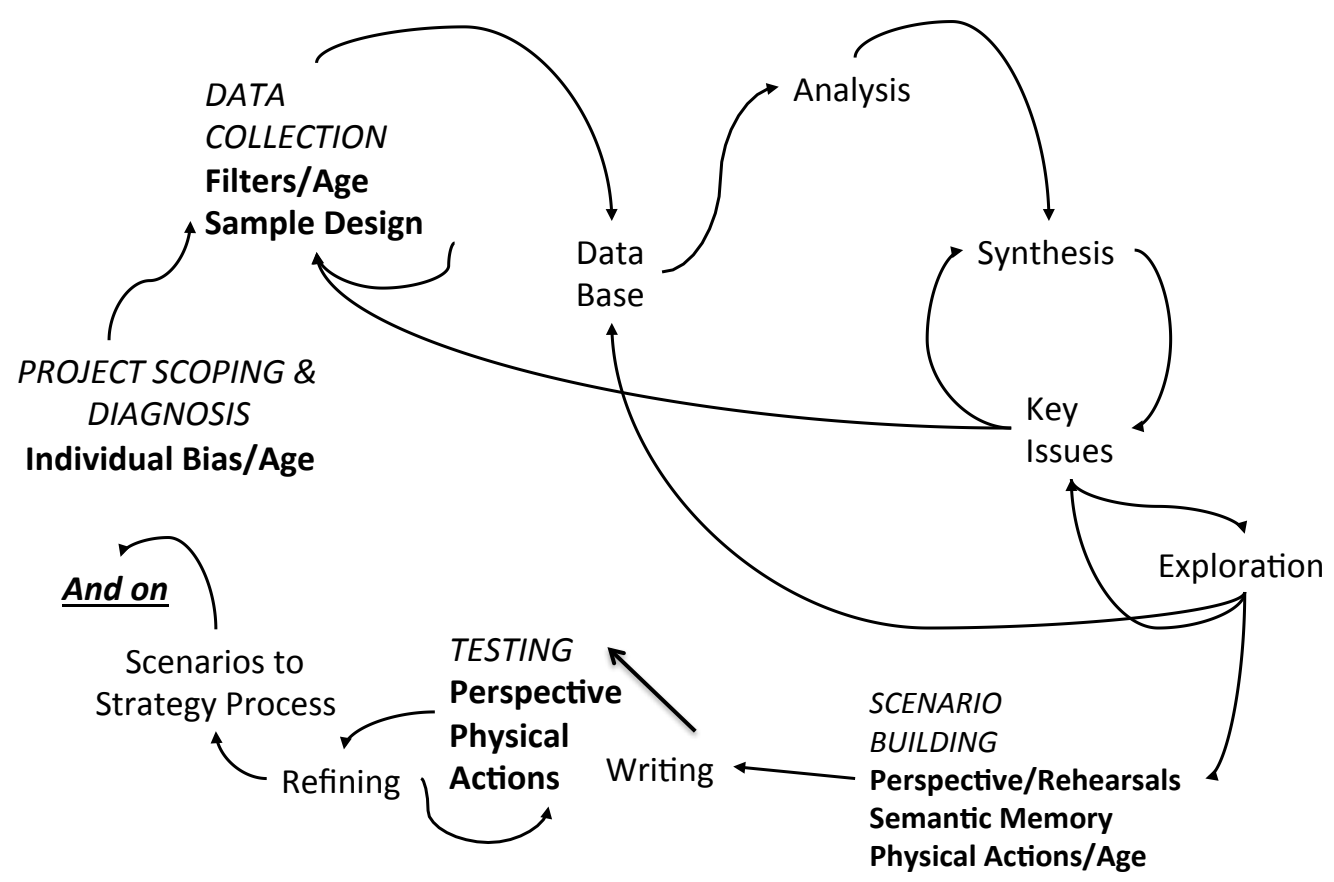

FIGURE 2 